\title{
Modified Barium Swallow Impairment Profile
}

National Cancer Institute

\section{Source}

National Cancer Institute. Modified Barium Swallow Impairment Profile. NCI Thesaurus. Code $C 127178$.

An evidence-based, standardization of the Modified Barium Swallow Study in adults. The protocol assesses 17 critical components of swallowing and provides an objective profile of the physiologic impairment affecting adult swallowing function. 